\title{
HUBUNGAN INTENSITAS KEBISINGAN DAN LAMA KERJA DENGAN KEJADIAN HIPERTENSI PADA TENAGA KERJA BAGIAN PRODUKSI PT. JAPFA COMFEED INDONESIA Tbk.
}

\author{
Andry Setiawan, Yohannes Joko S., Maharso \\ Poltekkes Kemenkes Banjarmasin Jurusan Kesehatan Lingkungan \\ Jl. H. Mistar Cokrokusumo No.1A Banjarbaru Kalimantan Selatan 70714 \\ E-mail: mr.fernando399@gmail.com
}

\begin{abstract}
The Relations of The Intensity of Noise And Work Term With The Hypertension Case of The Production Parts Employees In PT. Japfa Comfeed Indonesia Tbk.. Some research results prove that one of the risk factor of stroke is high blood pressure (hypertension). Noise pollution may be associated with the occurrence of hypertention, this is supported by an epidemiological study in the United States. The results of that study mentioned that people exposed to noise tend to have unstable emotions. Emotional instability will lead to a stress. If the stress happened long enough, it will cause the narrowing of blood vessels, so it will make the heart to work harder to pump blood throughout the body. In a long term, blood pressure will rise, and this is called Hypertension. The purpose of this study is to determine the relations between the intensity of noise pollution and work term with the case of hypertension in the production parts employee of PT. Japfa Comfeed Indonesia Tbk. Tanah Laut regency in 2017. The research method used is an analytical survey with cross sectional approach. The population in this study is amounted to 57 people and the sample amounted to 57 people. The results of this study indicates that there is a moderate relationship between the intensity of noise pollution with the incidence of hypertension ( $p$-value $=0,002<\alpha=0,05 r=0,407$ ), and there is a low relationship between work term with the incidence of hypertension ( $p$-value $=0,014<\alpha=0,05 r=0,323)$. Suggestions given to the company is to provide guidance on the use of PPE, perform routine health checks on employees and rotate the position of work on the employee of production.
\end{abstract}

Keywords: Hypertension; Intensity of Noise; Work Term.

\begin{abstract}
Abstrak: Hubungan Intensitas Kebisingan Dan Lama Kerja Dengan Kejadian Hipertensi Pada Tenaga Kerja Bagian Produksi PT. Japfa Comfeed Indonesia Tbk. Beberapa hasil penelitian membuktikan bahwa salah satu faktor risiko terjadinya penyakit stroke adalah tekanan darah tinggi (hipertensi). Kebisingan dapat berhubungan dengan terjadinya penyakit hipertensi, hal ini didukung dengan suatu studi epidemiologis di Amerika Serikat. Hasil penelitian tersebut menyebutkan bahwa masyarakat yang terpapar kebisingan, cenderung memiliki emosi yang tidak stabil. Ketidakstabilan emosi tersebut akan mengakibatkan stress. Stress yang cukup lama, akan menyebabkan terjadinya penyempitan pembuluh darah, sehingga memacu jantung untuk bekerja lebih keras memompa darah ke seluruh tubuh. Dalam waktu yang lama, tekanan darah akan naik, dan inilah yang disebut Hipertensi. Tujuan pada penelitian ini untuk mengetahui hubungan antara intensitas kebisingan dan lama kerja dengan kejadian hipertensi pada tenaga kerja bagian produksi PT. Japfa Comfeed Indonesia Tbk. kabupaten Tanah Laut tahun 2017. Metode penelitian yang digunakan adalah survey analitik dengan pendekatan cross sectional. Populasi dalam penelitian ini berjumlah 57 orang dan sampel berjumlah 57 orang. Hasil penelitian ini menunjukkan ada hubungan yang bersifat sedang antara intensitas kebisingan dengan kejadian hipertensi ( $p$-value $=0,002<\alpha=0,05 r=0,407)$, dan ada hubungan yang bersifat rendah antara lama kerja dengan kejadian hipertensi ( $p$-value $=0,014<\alpha=0,05 r=0,323$ ). Saran yang diberikan kepada pihak perusahaan yaitu memberikan pengarahan tentang penggunaan APD, melakukan cek kesehatan rutin pada tenaga kerja serta melakukan rotasi kerja pada tenaga kerja bagian produksi.
\end{abstract}

Kata Kunci : Hipertensi; Intensitas Kebisingan; Lama Kerja. 


\section{PENDAHULUAN}

Hipertensi yang tidak terkontrol akan menimbulkan berbagai komplikasi (1) yang merupakan salah satu penyakit pembuluh darah, sebagai silent killer, karena sering tidak menimbulkan gejala (2). Berdasarkan hasil Profil Data Kesehatan Indonesia 2012, hipertensi primer atau esensial menjadi salah satu penyakit dari 10 besar penyakit rawat inap di rumah sakit tahun 2011. Angka Case Fatality Rate (CFR) dari hipertensi pada tahun 2012 mencapai 4,81\%, ini artinya bahwa angka kematian akibat penyakit hipertensi masih cukup tinggi (3).

Hasil dari Riskesdas pada tahun 2013 Prevalensi hipertensi di Indonesia yang di dapat melalui pengukuran pada umur $\geq 18$ tahun sebesar 25,8\%, tertinggi di Bangka Belitung (30,09\%), diikuti Kalimantan Selatan (29,6\%), dan Jawa Barat (29,4\%). Dan melalui hasil penelitian dari Riskesdas tahun 2013 terhadap hipertensi menurut karakteristiknya didapat bahwa status pekerjaan juga dapat mempengaruhi terjadinya hipertensi dengan prevalensi sebesar $24,72 \%$ (4).

Kebisingan dapat berhubungan dengan terjadinya penyakit hipertensi. Hal ini didukung dengan suatu studi epidemiologis di Amerika Serikat. Antara ketidakstabilan emosi dengan terjadinya penyempitan pembuluh darah (5). Bising yang terus - menerus diterima seseorang akan menimbulkan gangguan proses fisiologis jaringan otot dalam tubuh dan memicu emosi yang tidak stabil. Ketidakstabilan emosi tersebut dapat memacu jantung untuk bekerja lebih keras memompa darah ke seluruh tubuh dalam waktu yang lama tekanan darah akan naik sehingga menyebabkan hipertensi (6).

Kebisingan yang dihasilkan oleh industri disebut Industrial Noise. Umumnya hal itu mempengaruhi kerja orang sekitar dan menciptakan masalah sangat serius (7). Adapun penelitian pada tenaga kerja bagian mesin bubuk di Moskwa dengan intensitas bising $93 \mathrm{~dB}$ didapatkan hasil tekanan darahnya dua kali lebih tinggi dari pada kelompok control (8). PT. Japfa Comfeed Indonesia Tbk. adalah salah satu industri yang berada di Kalimantan Selatan tepatnya di kabupaten Tanah Laut. Perusahaan ini bergerak dalam bidang produksi pakan ternak dengan merk dagang Comfeed dan Benefeed dengan kapasitas produksi sebesar 200.000 ton per tahun. Dalam proses produksinya digunakan mesinmesin yang menghasilkan bising dari tahap awal hingga akhir proses produksi dimulai dari proses Intake hingga proses packing. Hasil pengukuran tahun 2011, menunjukkan kebisingan di ruang produksi berkisar antara 60,3 dB hingga 90,3 dB.

Berdasarkan latar belakang tersebut penulis melakukan penelitian dengan tujuan untuk mengetahui hubungan antara pajanan intensitas kebisingan dan lama kerja dengan kejadian hipertensi pada tenaga kerja serta mengetahui faktor-faktor risiko lain hipertensi yang juga dapat berpengaruh terhadap tenaga kerja. Tenaga kerja yang diteliti mengalami gangguan emosional dan seluruh tempat bagian produksi yang ada di PT. Japfa Comfeed Indonesia Tbk. memiliki tingkat kebisingan diatas 60 $\mathrm{dbA}$.

\section{BAHAN DAN CARA PENELITIAN}

Hipertensi yang tidak terkontrol akan menimbulkan berbagai komplikasi (1) yang merupakan salah satu penyakit pembuluh darah, sebagai silent killer, karena sering tidak menimbulkan gejala (2). Berdasarkan hasil Profil Data Kesehatan Indonesia 2012, hipertensi primer atau esensial menjadi salah satu penyakit dari 10 besar penyakit rawat inap di rumah sakit tahun 2011. Angka Case Fatality Rate (CFR) dari hipertensi pada tahun 2012 mencapai 4,81\%, ini artinya bahwa angka kematian akibat penyakit hipertensi masih cukup tinggi (3).

Hasil dari Riskesdas pada tahun 2013 Prevalensi hipertensi di Indonesia yang di dapat melalui pengukuran pada umur $\geq 18$ tahun sebesar 25,8\%, tertinggi di Bangka Belitung (30,09\%), diikuti 
Kalimantan Selatan (29,6\%), dan Jawa Barat (29,4\%). Dan melalui hasil penelitian dari Riskesdas tahun 2013 terhadap hipertensi menurut karakteristiknya didapat bahwa status pekerjaan juga dapat mempengaruhi terjadinya hipertensi dengan prevalensi sebesar $24,72 \%$ (4).

Kebisingan dapat berhubungan dengan terjadinya penyakit hipertensi. Hal ini didukung dengan suatu studi epidemiologis di Amerika Serikat. Antara ketidakstabilan emosi dengan terjadinya penyempitan pembuluh darah (5). Bising yang terus - menerus diterima seseorang akan menimbulkan gangguan proses fisiologis jaringan otot dalam tubuh dan memicu emosi yang tidak stabil. Ketidakstabilan emosi tersebut dapat memacu jantung untuk bekerja lebih keras memompa darah ke seluruh tubuh dalam waktu yang lama tekanan darah akan naik sehingga menyebabkan hipertensi (6).

Kebisingan yang dihasilkan oleh industri disebut Industrial Noise. Umumnya hal itu mempengaruhi kerja orang sekitar dan menciptakan masalah sangat serius (7). Adapun penelitian pada tenaga kerja bagian mesin bubuk di Moskwa dengan intensitas bising $93 \mathrm{~dB}$ didapatkan hasil tekanan darahnya dua kali lebih tinggi dari pada kelompok control (8). PT. Japfa Comfeed Indonesia Tbk. adalah salah satu industri yang berada di Kalimantan Selatan tepatnya di kabupaten Tanah Laut. Perusahaan ini bergerak dalam bidang produksi pakan ternak dengan merk dagang Comfeed dan Benefeed dengan kapasitas produksi sebesar 200.000 ton per tahun. Dalam proses produksinya digunakan mesin- mesin yang menghasilkan bising dari tahap awal hingga akhir proses produksi dimulai dari proses Intake hingga proses packing. Hasil pengukuran tahun 2011, menunjukkan kebisingan di ruang produksi berkisar antara 60,3 dB hingga 90,3 dB.

Berdasarkan latar belakang tersebut penulis melakukan penelitian dengan tujuan untuk mengetahui hubungan antara pajanan intensitas kebisingan dan lama kerja dengan kejadian hipertensi pada tenaga kerja serta mengetahui faktor-faktor risiko lain hipertensi yang juga dapat berpengaruh terhadap tenaga kerja. Tenaga kerja yang diteliti mengalami gangguan emosional dan seluruh tempat bagian produksi yang ada di PT. Japfa Comfeed Indonesia Tbk. memiliki tingkat kebisingan diatas 60 $\mathrm{dbA}$.

\section{HASIL PENELITIAN DAN PEMBAHASAN}

Hasil pengukuran intensitas kebisingan pada 3 lantai ruang produksi terdapat 2 lantai yang tingkat kebisingannya tidak melebihi NAB yaitu lantai 1 proses produksi press dan packing dengan jumlah tenaga kerja 32 orang intensitas kebisingan sebesar $(79,2 \mathrm{~dB})$ dan lantai 2 proses produksi dosing dengan jumlah tenaga kerja 17 orang intensitas kebisingan $(80,1 \mathrm{~dB})$. Sedangkan pengukuran yang dilakukan pada lantai 3 dengan jumlah tenaga kerja 8 orang proses produksi intake dan grinding menunjukkan intensitas kebisingan yang melebihi NAB yaitu sebesar $(88,2 \mathrm{~dB})$ selengkapnya dapat dilihat pada tabel 1 :

Tabel 1. Distribusi intensitas kebisingan tenaga kerja bagian produksi PT. Japfa Comfeed Indonesia Tbk. Tahun 2017

\begin{tabular}{ccccc}
\hline No & Intensitas Kebisingan & Lantai & $\begin{array}{c}\text { Frekuensi } \\
\text { (Tenaga Kerja) }\end{array}$ & $\begin{array}{c}\text { Persentase } \\
(\%)\end{array}$ \\
\hline 1 & $\leq 85 \mathrm{~dB}$ & 1 dan 2 & 49 & 88,7 \\
2 & $>85 \mathrm{~dB}$ & 3 & 8 & 10,3 \\
& Jumlah & 3 & 57 & 100 \\
\hline
\end{tabular}


Berdasarkan tabel 1 menunjukkan, sebagian besar tenaga kerja terpapar bising tidak melebihi NAB, sementara ada 8 orang tenaga kerja $(10,3 \%)$ terpapar bising melebihi NAB.
Hasil wawancara lama kerja dengan 57 orang tenaga kerja dengan klasifikasi baru dan lama. Tabel 2 berikut menyajikan distribusi berdasarkan lama kerjanya selengkapnya dapat dilihat pada tabel 2

Tabel 2. Distribusi lama kerja tenaga kerja bagian produksi PT. Japfa Comfeed Indonesia Tbk. Tahun 2017

\begin{tabular}{cccc}
\hline No & Lama Kerja & Frekuensi (Orang) & Persentase (\%) \\
\hline 1 & Baru ( $\leq 3$ Tahun) & 11 & 19,3 \\
2 & Lama ( > 3 Tahun) & 46 & 80,7 \\
& Jumlah & 57 & 100 \\
\hline
\end{tabular}

Berdasarkan tabel 2 menunjukkan sebagian besar tenaga kerja bagian produksi PT. Japfa Comfeed Indonesia Tbk. bekerja sudah cukup lama yaitu dengan presentase sebesar $80,7 \%$.
Hasil wawancara usia dengan 57 orang tenaga kerja menunjukkan usia yang bervariasi. Tabel 3 berikut menyajikan distribusi berdasarkan usia

Tabel 3. Distribusi usia tenaga kerja bagian produksi PT. Japfa Comfeed Indonesia Tbk. Tahun 2017

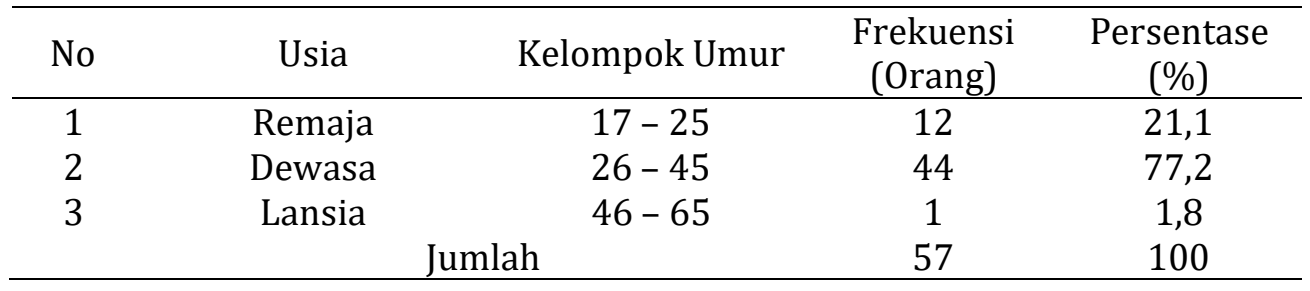

Berdasarkan tabel 3 diatas menunjukkan sebagian besar tenaga kerja PT. Japfa Comfeed Indonesia Tbk. berada dalam rentang usia dewasa yaitu dengan presentase $77,2 \%$.
Hasil wawancara pendidikan dengan 57 orang tenaga kerja menunjukkan tingkat pendidikan yang bervariasi. Tabel 4 berikut menyajikan distribusi berdasarkan pendidikan selengkapnya dapat dilihat pada tabel 4

Tabel 4. Distribusi tingkat pendidikan tenaga kerja bagian produksi PT. Japfa Comfeed Indonesia Tbk. Tahun 2017

\begin{tabular}{cccc}
\hline No & Pendidikan & Frekuensi (Orang) & Persentase (\%) \\
\hline 1 & SLTP & 5 & 8,8 \\
2 & SLTA & 45 & 78,9 \\
3 & Sarjana & 7 & 12,3 \\
& Jumlah & 57 & 100 \\
\hline
\end{tabular}

Berdasarkan tabel 4 menunjukkan sebagian besar tenaga kerja bagian produksi PT. Japfa Comfeed Indonesia Tbk. mempunyai tingkat pendidikan SLTA (78,9\%).

Hasil wawancara jenis kelamin pada 57 orang tenaga kerja menunjukkan jenis kelamin tenaga kerja yang ada di unit produksi PT. Japfa Comfeed Indonesia Tbk. Tabel 5 berikut menyajikan distribusi berdasarkan jenis kelamin selengkapnya dapat dilihat pada tabel 5 
Andry Setiawan, Yohannes Joko S., Maharso. Abstrak: Hubungan Intensitas Kebisingan Dan Lama Kerja Dengan Kejadian Hipertensi Pada Tenaga Kerja Bagian

Produksi PT. Japfa Comfeed Indonesia Tbk

Tabel 5. Distribusi jenis kelamin tenaga kerja bagian produksi PT. Japfa Comfeed Indonesia Tbk. Tahun 2017

\begin{tabular}{cccc}
\hline No & Jenis Kelamin & Frekuensi (Orang) & Persentase (\%) \\
\hline 1 & Laki-Laki & 51 & 89,5 \\
2 & Perempuan & 6 & 10,5 \\
& Jumlah & 57 & 100 \\
\hline
\end{tabular}

Berdasarkan tabel 5 menunjukkan sebagian besar tenaga kerja bagian produksi PT. Japfa Comfeed Indonesia Tbk. berjenis kelamin laki-laki dengan persentase sebesar $89,5 \%$.
Hasil wawancara jam kerja dengan 57 orang tenaga kerja menunjukkan jam kerja para tenaga kerja berkisar antara 7,8 dan 9 jam. Tabel 6 berikut menyajikan distribusi berdasarkan jam kerjanya selengkapnya dapat dilihat pada tabel 6

Tabel 6 Distribusi jam kerja tenaga kerja bagian produksi PT. Japfa Comfeed Indonesia Tbk. Tahun 2017

\begin{tabular}{cccc}
\hline No & Jam Kerja ( Jam/Hari) & Frekuensi (Orang) & Persentase (\%) \\
\hline 1 & 7 & 17 & 29,8 \\
2 & 8 & 36 & 63,2 \\
3 & 9 & 4 & 7,0 \\
& Jumlah & 57 & 100 \\
\hline
\end{tabular}

Berdasarkan tabel 6 menunjukkan sebagian besar tenaga kerja bagian produksi PT. Japfa Comfeed Indonesia Tbk. Bekerja selama 8 jam sehari dengan persentase $63,2 \%$.

Pengukuran tentang kejadian hipertensi tenaga kerja dengan dibagi menjadi 4 kelompok ( Normal, Pre-
Hipertensi, Hipertensi Tahap 1, Hipertensi Tahap 2) diperoleh data kejadian hipertensi dari 57 orang tenaga kerja. Tabel 7 berikut menyajikan distribusi berdasarkan tingkat hipertensinya selengkapnya dapat dilihat pada tabel 7

Tabel 7. Distribusi Hipertensi tenaga kerja bagian produksi PT. Japfa Comfeed Indonesia Tbk. Tahun 2017

\begin{tabular}{cccc}
\hline No & Hipertensi & Frekuensi (Orang) & Persentase (\%) \\
\hline 1 & Normal & 24 & 42,1 \\
2 & Pre - Hipertensi & 27 & 47,4 \\
3 & Hipertensi tahap 1 & 5 & 8,8 \\
4 & Hipertensi tahap 2 & 1 & 1,8 \\
& Jumlah & 57 & 100 \\
\hline
\end{tabular}

Berdasarkan tabel 7 menunjukkan sebagian besar para tenaga kerja mengalami hipertensi baik itu pre hipertensi, hipertensi tahap 1 maupun hipertensi tahap 2 dengan presentase tertinggi yaitu pre-hipertensi $(47,4 \%)$.

Hasil pengukuran tentang berat badan dan tinggi badan tenaga kerja digunakan untuk menentukan Body Mass Index tenaga kerja yang akan digunakan untuk memperoleh data obesitas dari 57 orang tenaga kerja. Tabel 8 berikut menyajikan distribusi berdasarkan tingkat obesitasnya selengkapnya dapat dilihat pada tabel 8 . 
Tabel 8. Distribusi obesitas tenaga kerja bagian produksi PT. Japfa Comfeed Indonesia Tbk. Tahun 2017

\begin{tabular}{cccc}
\hline No & Obesitas & Frekuensi (Orang) & Persentase (\%) \\
\hline 1 & Ya & 4 & 7 \\
2 & Tidak & 53 & 93 \\
& Jumlah & 57 & 100 \\
\hline
\end{tabular}

Berdasarkan tabel 8 menunjukkan sebagian besar para tenaga kerja tidak mengalami obesitas, tenaga kerja yang tidak mengalami obesitas berjumlah 53 orang (93\%).
Hasil wawancara tentang riwayat hipertensi dengan 57 orang tenaga kerja menunjukkan riwayat hipertensi tenaga kerja. Tabel 9berikut menyajikan distribusi berdasarkan riwayat hipertensinya selengkapnya dapat dilihat pada tabel 9.

Tabel 9. Distribusi riwayat hipertensi tenaga kerja bagian produksi PT. Japfa Comfeed Indonesia Tbk. Tahun 2017

\begin{tabular}{cccc}
\hline No & $\begin{array}{c}\text { Mempunyai Riwayat Hipertensi / } \\
\text { Anggota Keluarga Hipertensi }\end{array}$ & $\begin{array}{c}\text { Frekuensi } \\
\text { (Orang) }\end{array}$ & $\begin{array}{c}\text { Persentase } \\
(\%)\end{array}$ \\
\hline 1 & Ya & 13 & 22,8 \\
2 & Tidak & 44 & 77,2 \\
& Jumlah & 57 & 100 \\
\hline
\end{tabular}

Berdasarkan tabel 9 menunjukkan sebagian besar tenaga kerja tidak mempunyai riwayat hipertensi ataupun mempunyai keluarga yang mempunyai riwayat hipertensi sebelumnya dengan persentase $77,2 \%$.

Hasil wawancara kepada tenaga kerja bagian produksi PT. Japfa Comfeed Indonesia Tbk. tentang kebiasaan merokok per 15 batang perhari, kurang dari 15 batang perhari dan kebiasaan tidak merokok, dengan jumlah 57 orang tenaga kerja. Tabel 10 berikut ini menyajikan distribusi frekuensi berdasarkan kebiasaan merokok per 15 batang perhari, kurang dari 15 batang perhari dan kebiasaan tidak merokok tenaga kerja, selengkapnya dapat dilihat pada tabel 10 .

Tabel 10. produksi PT. Japfa Comfeed Indonesia Tbk. Tahun 2017

\begin{tabular}{cccc}
\hline No & Kebiasaan Merokok perhari & Frekuensi (Orang) & Persentase (\%) \\
\hline 1 & > 15 Batang & 16 & 28,1 \\
2 & < 15 Batang & 5 & 8,8 \\
3 & Tidak Merokok & 36 & 63,2 \\
& Jumlah & 57 & 100 \\
\hline
\end{tabular}

Berdasarkan tabel 10 menunjukkan sebagian besar para tenaga kerja tidak merokok, dengan jumlah 36 orang $(63,2 \%)$.

Berdasarkan pengukuran tekanan darah dan pengukuran kebisingan pada proses produksi PT. Japfa Comfeed Indonesia Tbk. yang dilakukan pada 57 orang tenaga kerja menunjukkan dari $19,3 \%$ tenaga kerja yang bekerja dengan intensitas kebisingan melebihi NAB diperoleh 19,3\% mengalami Hipertensi dengan pembagian $14,1 \%$ pre-hipertensi dan 5,2\% Hipertensi tahap 1. Dan dari $80,7 \%$ tenaga kerja yang bekerja dengan paparan intensitas kebisingan tidak melebihi NAB diperoleh 38,6\% mengalami Hipertensi dengan pembagian $33,3 \%$ pre-hipertensi, 3,5\% hipertensi tahap 1, dan 1,8\% hipertensi tahap 2. 
Andry Setiawan, Yohannes Joko S., Maharso. Abstrak: Hubungan Intensitas Kebisingan Dan Lama Kerja Dengan Kejadian Hipertensi Pada Tenaga Kerja Bagian

Produksi PT. Japfa Comfeed Indonesia Tbk

Tabel 11. Distribusi kejadian Hipertensi tenaga kerja berdasarkan Intensitas kebisingan pada tenaga kerja bagian produksi PT. Japfa Comfeed Indonesia Tbk. Tahun 2017

\begin{tabular}{ccccccc}
\hline No & Kebisingan & Normal & $\begin{array}{c}\text { Pre- } \\
\text { Hipertensi }\end{array}$ & $\begin{array}{c}\text { Hipertensi } \\
\text { Tahap 1 }\end{array}$ & $\begin{array}{c}\text { Hipertensi } \\
\text { Tahap 2 }\end{array}$ & $\begin{array}{c}\text { Persentase } \\
(\%)\end{array}$ \\
\hline 1 & $<85 \mathrm{~dB}$ & 24 & 22 & 2 & 1 & 80,7 \\
2 & $>85 \mathrm{~dB}$ & 0 & 5 & 3 & 0 & 19,3 \\
& Jumlah & 24 & 27 & 5 & 1 & 100 \\
\hline
\end{tabular}

Hasil uji statistik menggunakan uji korelasi rank spearman didapatkan hasil nilai $\mathrm{p}=0,002<\alpha=0,05$ dan nilai $r$ menunjukkan hasil 0,407 yang artinya terdapat korelasi yang sedang antar variabel. Berdasarkan hasil uji tersebut dapat disimpulkan bahwa $\mathrm{HO}$ ditolak yang berarti terdapat hubungan yang bermakna antara intensitas kebisingan dengan kejadian Hipertensi pada tenaga kerja bagian produksi PT. Japfa Comfeed Indonesia Tbk. Tahun 2017. Dan Berdasarkan hasil uji statistik didapatkan nilai $r=0,407$ dan $r 2=0,168$, maka dapat diketahui bahwa terdapat $16,8 \%$ tenaga kerja bagian produksi PT. Japfa Comfeed Indonesia Tbk. yang mengalami hipertensi berdasarkan paparan intensitas kebisingan dan 83,9\% tenaga kerja bagian produksi tidak mengalami hipertensi berdasarkan paparan intensitas kebisingan.

Berdasarkan pengukuran tekanan darah dan wawancara lama kerja pada 57 orang tenaga kerja pada proses produksi PT. Japfa Comfeed Indonesia Tbk. Selengkapnya dapat dilihat pada tabel 12 .

Tabel 12. Distribusi kejadian Hipertensi tenaga kerja berdasarkan Lama kerja pada tenaga kerja bagian produksi PT. Japfa Comfeed Indonesia Tbk. Tahun 2017

\begin{tabular}{|c|c|c|c|c|c|c|}
\hline No & Lama Kerja & Normal & $\begin{array}{c}\text { Pre- } \\
\text { Hipertensi }\end{array}$ & $\begin{array}{c}\text { Hipertensi } \\
\text { Tahap } 1\end{array}$ & $\begin{array}{l}\text { Hipertensi } \\
\text { Tahap } 2 \\
\end{array}$ & $\begin{array}{c}\text { Persentase } \\
(\%)\end{array}$ \\
\hline 1 & $\begin{array}{l}\text { Baru } \\
\text { tahun })\end{array} \quad 3$ & 8 & 3 & & 0 & 80,7 \\
\hline 2 & $\begin{array}{l}\text { Lama } \\
\text { tahun })\end{array} \quad(>3$ & 16 & 24 & 5 & 1 & 19,3 \\
\hline & Jumlah & 24 & 27 & 5 & 1 & 100 \\
\hline
\end{tabular}

Hasil uji statistik menggunakan uji korelasi rank spearman didapatkan hasil nilai $p=0,014<\alpha=0,05$ dan nilai $r$ menunjukkan hasil 0,323 yang artinya terdapat korelasi yang rendah antar variabel. Berdasarkan hasil uji tersebut dapat disimpulkan bahwa $\mathrm{HO}$ ditolak yang berarti terdapat hubungan yang bermakna antara lama kerja dengan kejadian Hipertensi pada tenaga kerja bagian produksi PT. Japfa Comfeed

\section{KESIMPULAN DAN SARAN}

Berdasarkan hasil pengamatan dan analisis data pada penelitian yang telah dilakukan dapat disimpulkan bahwa dari 3 lantai ruang produksi yang diukur intensitas kebisingannya bahwa terdapat
Indonesia Tbk. Tahun 2017. Dan Berdasarkan hasil uji statistik didapatkan nilai $r=0,323$ dan $r^{2}=0,104$, maka dapat diketahui bahwa terdapat $10,4 \%$ tenaga kerja bagian produksi PT. Japfa Comfeed Indonesia Tbk. yang mengalami hipertensi berdasarkan lama kerja dan $89,7 \%$ tenaga kerja bagian produksi tidak mengalami hipertensi berdasarkan lama kerjanya.

dua lantai dengan jumlah tenaga kerja 49 orang, persentasi $88,7 \%$ yang intensitas kebisingannya tidak melebihi $\mathrm{NAB}$, dan satu lantai dengan jumlah tenaga kerja 8 orang persentasi $10,3 \%$ intensitas kebisingannya melebihi NAB. Dari 57 orang tenaga kerja tentang lama 
bekerjanya mulai masuk sampai dengan sekarang terdapat 46 orang tenaga kerja dengan persentasi $80,7 \%$ masuk dalam kategori lama ( $>3$ tahun) dan 11 orang dengan persentasi 19,3\% masuk dalam kategori tenaga kerja baru ( $\leq 3$ tahun). Dari 57 orang tenaga kerja yang diukur tingkat tekanan darahnya sebanyak 33 orang dengan persentasi $58 \%$ mengalami kejadian hipertensi baik itu prehipertensi, hipertensi tahap 1, maupun hipertensi tahap 2. Terdapat 24 orang tenaga kerja dengan persentasi $42 \%$ tidak mengalami hipertensi atau tekanan darahnya normal.

Terdapat hubungan yang bermakna antara intensitas kebisingan dengan kejadian hipertensi pada tenaga kerja bagian produksi PT. Japfa Comfeed Indonesia Tbk. tahun 2017 dimana nilai $p$ $=0,002<\alpha=0,05$ dan nilai $r$ menunjukkan hasil 0,407 dan termasuk dalam kategori sedang dan terdapat hubungan yang bermakna antara lama kerja dengan kejadian hipertensi pada tenaga kerja bagian produksi PT. Japfa Comfeed Indonesia Tbk. tahun 2017 dmana nilai $p$ $=0,014>\alpha=0,05$ dan nilai $r$ menunjukkan hasil 0,323 dan termasuk dalam kategori rendah

Perusahaan menetapkan peraturan yang ketat tentang penggunaan alat pelindung diri saat bekerja dan melakukan pengarahan guna menambah pengetahuan tentang penyakit akibat kerja. Melakukan cek kesehatan rutin setiap bulannya untuk mengetahui kemungkinan terjadinya kejadian hipertensi akibat stress dengan kebisingan sebagai pemicunya. Melakukan rotasi posisi tenaga kerja dimana apabila diketahui tingkat tekanan darah tenaga kerja tersebut sudah cukup tinggi. Pengaturan jam kerja pada tenaga kerja yang bekerja selama 8 jam dengan intensitas bising diatas NAB yaitu proses produksi pada lantai 3 dengan intensitas kebisingan sebesar $88 \mathrm{~dB}$, sesuai dengan Permenaker no 13 tahun 2011 yang menyatakan bahwa tenaga kerja hanya diperbolehkan untuk bekerja selama 4 jam dalam sehari dan bagi tenaga Kerja Bagian Produksi menggunakan APD berupa ear plug atau ear muff dan mengatur waktu untuk keluar dari ruang produksi agar tidak terpapar bising secara terus menerus.

\section{KEPUSTAKAAN}

1. Nuraini, B. 2015. Risk Factors of Hypertensions. Jurnal Penelitian. Vol 04. No. 05. 2015

2. Harianto E, Hadi P. 2013. Pajanan kebisingan dan hipertensi di kalangan pekerja pelabuhan. Jurnal Kesehatan Masyarakat Nasional 8(5) : 215-220.

3. Depkes RI, 2009. Sistem Kesehatan Nasional. Jakarta.

4. Sinubu R., Rolly R., Onibala F. 2015. Hubungan Beban Kerja Dengan Kejadian Hiprtensi pada Tenaga Pengajar di SMAN 1 Amurang Kabupaten Minahasa Selatan. EJournal Keperawatan Vol 3 No (2).

5. Haryoto, 2005. Hipertensi Akibat Bising (Jurnal Online); diakses 24 Januari 2017

6. Zulharmans, Russeng S, Wahyuni A. 2015. Hubungan Kebisingan Pada Tekanan Darah Pada Karyawan Bagian Produksi PT.Semen Tonasa. Jurnal Media Kesehatan.

7. Lavanya C, Dankar R, Chikkara S. 2014. Noise Pollution. Jurnal Penelitian Internasional. Vol 06. Issue 05. 2014

8. Babba, J. 2004. Hubungan Intensitas Kebisingan Lingkungan Kerja Dengan peningkatan Tekanan Darah (Penelitian pada Karyawan PT.Semen Tonasa di Kabupaten Pangkep. Sulawesi Selatan.(Tesis). Universitas Diponegoro Semarang

9. Alhusin, S. 2003. Aplikasi Statistik Dengan SPSS.13 for Windows. Yogyakarta: Penerbit Graha Ilmu. 